\title{
BAŞ AĞRILI BİREYLERDE SERVIKAL KAS İSKELET SİSTEMİ BOZUKLUKLARI
}

\author{
Hülya ALTMIŞ⿻1, Arzu GÜÇLÜ GÜNDÜZ ${ }^{1}$ \\ ${ }^{1}$ Gazi Üniversitesi, Sağllk Bilimleri Fakültesi, Fizyoterapi ve Rehabilitasyon Bölümü, Ankara, Türkiye
}

\begin{abstract}
ÖZET
Baş ağrisı toplumda yaygın görülen, birçok etkene bağl1, bireysel ve sosyo-ekonomik etkileri oldukça fazla genel bir sağlık problemidir. Baş ağrılı bireylerde boyun ağrısının yüksek prevelansının, son yıllarda bu hastalarda servikal bölge yapılarının incelenmesine yönelik çalışmaları artırdığı görülmektedir. Bu derleme sık görülen baş ağrısı tipleri olan Gerilim Tipi Baş Ağrısı (GTBA), migren ve Servikojenik Baş Ağrısı (SBA) ile servikal kas iskelet sistemi bozuklukları arasındaki ilişkiyi incelemek amacıyla yapılmıştır. GTBA'lı hastalarda ileri baş postürü, azalmış servikal mobilite, yetersiz servikal kas fonksiyonu, artmış tetik nokta sayısı, kas hassasiyeti ve düşük basınç ağrı eşiği gibi servikal kas iskelet sistemi bozukluklarının birçok çalışmada bildirildiği görülmektedir. Diğer taraftan az sayıda da olsa, yüzeyel kas kuvveti değerlendirmesinde bu hastaların sağlıklı bireylerden farklı olmadığını bildiren çalışmalar bulunmaktadır. Migrenli hastalarda da ileri baş postürü, azalmış servikal mobilite, yetersiz servikal kas fonksiyonu ve servikal esneklik, artmış tetik nokta sayısı ve düşük basınç ağrı eşiği bulunduğu birçok çalışmada bildirilmektedir. Fakat bazı çalışmalarda migrenli hastalarda ileri baş postürü ve yüzeyel servikal kas kuvvetinde azalma görülmediği belirtilmektedir. SBA ise servikal omurga ile en ilişkili baş ağrısı tipi olmasına karşın, bu hastalarda servikal kas iskelet sistemi bozuklukları sonuçlarının daha çelişkili ve konuyla ilgili güncel verilerin yetersiz olduğu görülmektedir. SBA hastalarında ileri baş postürü, azalmış servikal mobilite ve yetersiz kas fonksiyonu birçok çalışmada bildirilirken, bazı çalışmalar bu hastalarda ileri baş postürü olmadığını belirtmektedir. Sonuç olarak; GTBA, migren ve SBA servikal kas iskelet sistemi bozuklukları ile ilişkili görünmektedir. Bu hastalarda servikal kas iskelet sistemi değerlendirmesinin önemli olduğunu düşünmekteyiz.
\end{abstract}

Anahtar Kelimeler: Baş ağrısı, servikal bölge, kas iskelet sistemi bozuklukları

\section{CERVICAL MUSCULOSKELETAL DYSFUNCTIONS IN INDIVIDUALS WITH HEADACHE}

\begin{abstract}
Headache is a common health problem with many individual and socio-economic effects. The high prevalence of neck pain in individuals with headache has been observed to increase studies examination of cervical region structures in headache patients in recent years. This review was conducted to examine relationship between Tension Type Headache (TTH), migraine and Cervicogenic Headache (CGH), which are common types of headache, and cervical musculoskeletal disorders. Cervical musculoskeletal disorders as forward head posture (FHP), decreased cervical mobility, insufficient cervical muscle function, increased number of trigger points (TP), muscle tenderness and low pressure pain threshold (PPT) have been reported in many studies in TTH patients. Otherwise, few studies have reported these patients are not different from healthy individuals in assessment of superficial muscle strength. It has been reported in many studies cervical musculoskeletal system disorders include FHP, decreased cervical mobility, insufficient cervical muscle function and cervical flexibilty, increased number TP and low PPT in migraine patients. Conversely, several studies have reported migraine patients do not have FHP and decrease superficial cervical muscle strength. Although CGH is the most associated headache subgroup with cervical spine, results of cervical musculoskeletal disorders are contradictory and current data is insufficient. While results of FHP, decreased cervical mobility and insufficient muscle function are more pronounced in CGH patients, some studies have reported that there is no FHP. In conclusion; TTH, migraine and CGH appear to be associated with cervical musculoskeletal disorders. We think that evaluations cervical musculoskeletal disorders are important in headache patients.
\end{abstract}

Keywords: Headache, cervical region, musculoskeletal system disorders

Iletişim/Correspondence

Hülya ALTMIŞ

Gazi Üniversitesi, Sağlık Bilimleri Fakültesi

Fizyoterapi ve Rehabilitasyon Bölümü, Ankara, Türkiye
E-posta: fzt-hulyaaltmis@hotmail.com Geliş tarihi/Received: 05.02.2021 Kabul tarihi/Accepted: 03.04.2021 DOI: $10.52881 /$ gsbdergi.873465 


\section{GíRIŞ}

Baş ağrısı, farklı yaş gruplarında görülebilen, sık karşılaşılan, birçok etkene bağl1, bireysel ve sosyo-ekonomik etkileri oldukça fazla olan genel bir sağlık problemidir (1, 2). Baş ağrısının, bireylerde önemli ölçüde ağrıya ve buna bağlı engelliliğe neden olduğu ve sağlık hizmetleri sistemlerinde önemli maliyetler oluşturduğu bildirilmektedir (3). Ömür boyu en az bir kez baş ağrısı yaşayan bireylerin oranının erkeklerde \%93, kadınlarda \%99 olmak üzere genel populasyonda \%90'ın üzerinde olduğu belirtilmektedir (4).

Uluslararası Baş Ağrısı Topluluğu, baş ağrılarını primer ve sekonder baş ağrıları olarak iki ana başlık altında sınıflandırmaktadır (3). Epidemiyolojik çalışmalar en yaygın primer baş ağrısı tipini $\% 20,77$ görülme sıklığı ile gerilim tipi baş ağrısı (GTBA) ve ikincisini \%14,7 görülme sıklığı ile migren olarak bildirmektedir (5, 6). S1k görülen sekonder baş ağrısı tiplerinden biri olan servikojenik baş ağrısının (SBA) ise, servikal bölge ile ilişkili problemlerden kaynaklanan baş ağrisı olup, genel populasyonun \%2,5'inde ve sıkça baş ağrısı yaşayanların \%17,8'inde görüldüğü belirtilmektedir (7).

GTBA, migren ve SBA hastalarında boyun ağrısı ve servikal bölge disfonksiyonlarının birçok araştırmaya konu olduğu, farklı baş ağrısı tiplerinde servikal bölge kas iskelet sistemi bozukluklarının baş ağrısı ile ilişkisini inceleyen çalışmaların her geçen gün $\operatorname{arttığ~}$ görülmektedir $(8,9)$.

$\mathrm{Bu}$ derlemede gerilim tipi baş ağrısı, migren ve servikojenik baş ağrısı hastalarında görülen servikal kas iskelet sistemi bozukluklarının güncel veriler 1şığında incelenmesi hedeflenmektedir.

\section{Baş Ăgrısı ve Boyun Ağrısı Arasındaki İlişki}

Baş ağrılı hastalarda boyun ağrısı varlığ1 birçok çalışmada gösterilmektedir. Yakın zamanda yapılan bir açık populasyon çalışmasında, boyun ağrısı prevalansının migrenli bireylerde \%76,2 GTBA'11 bireylerde \%88,4 olduğu ve ayrıca migrenli ve GTBA'lı bireylerde boyun ağrıs1 oranının baş ağrısı olmayan bireylere göre daha yüksek olduğu bildirilmektedir (10). Başka bir çalışmada da migren hastalarında boyun ağrısı prevalansı yaklaşık \%76 olarak bildirilmekte ve boyun ağrısının baş ağrısından önce başladığ veya baş ağrıs1 fazına eşlik ettiği belirtilmektedir. Boyun ağrısının migren atakları sırasında mide bulantısından daha yaygın olduğu ve migren hastalarında özürlülüğün önemli bir belirleyicisi olduğu bildirilmektedir (1113).

Baş ağrısı ile boyun ağrısı arasındaki ilişkinin altında yatan mekanizmalar incelendiğinde, en kabul gören hipotezin spinal trigeminal çekirdekte trigeminal sinirin ve üst servikal (C) 1-3 sinirlerin primer afferent girdilerinin birleşmesi olduğu görülmektedir. Üst servikal yap1lardan gelen nosiseptif duyu girdileri ile baş ve yüze ait nosiseptif duyu girdilerinin trigeminal nukleusta birleşmesi bir bölgeden gelen ağrı sinyalinin diğer bölgeye yayılmasına, ayrıca ağrıya duyarlılığının artmasına ve normalde ağrısız olan uyaranlara karşı ağrı cevabının oluşmasına neden olmaktadır (13-15). Bu nedenle servikal yapılardan kaynaklanan bir nosiseptif girdinin baş ağrısını tetikleyebileceği, ya da tam tersi baş ağrısının servikal bölgeye yayılabileceği düşünülmektedir.

Son yıllarda, boyun ağrısının baş ağrılarındaki rolüne yönelik ilgi ve 
araştırmaların arttı̆̆1; ayrıca baş ağrısı ve boyun ağrısı arasındaki ilişkinin daha anlaşılabilir hale gelmesi için baş ağrılı hastalarda servikal kas iskelet sistemi bozukluklarının belirlenmesine yönelik çalışmaların da arttı̆̆ı görülmektedir. Baş ağrılı hastalarda görülen boyun ağrısının servikal kas iskelet sistemi yapılarından kaynaklanan bir ağrı mı yoksa baş ağrısına bağlı bir periferik veya santral sensitizasyon sonucunda hissedilen bir ağrı mı olduğu hala tartışmalıdır. Baş ve boyun ağrısı arasındaki çift yönlü ilişkinin daha net anlaşılabilmesi için baş ağrılı hastalarda servikal kas iskelet sistemi bozukluklarının belirlenmesi önemli görünmektedir.

Aşağıda bu üç baş ağrısı tipinde sıça karşılaşılan servikal kas iskelet sistemi bozuklukları sunulmaktadır.

\section{Gerilim Tipi Baş Ağrısı}

Gerilim tipi baş ağrısı bütün primer baş ağrıları içinde en sık rastlanılan baş ağrısıdır (1). Patofizyolojik açıdan bakıldığında ilk mekanizma olarak, baş ve boyun kaslarındaki gerginlik ve kaslar içindeki ağrıyı tetikleyen aktif tetik noktalardan gelen nosiseptif uyarının başa yayılan ağriya neden olduğu bildirilmektedir (16). Primer olarak kas kökenli bir baş ağrısı olduğu düşünülmekle birlikte sadece kas kökenli olmadığı, patofizyolojide trigeminal sinirin motor ve duyu nöronları arasındaki internöronlarda anormal bir modülasyon bulunduğu da düşünülmektedir. $\mathrm{Bu}$ anormalliğin bazal gangliadan, limbik sistemden veya dorsal raphe nukleusundaki serotoninerjik nöronlardan kaynaklanabileceği belirtilmektedir. Ayrıca duyarlılı̆̆ artmış perikranyal miyofasyal dokulardan gelen nosiseptif uyarının üst servikal sinirler ve spinal trigeminal nukleusta sensitizasyona yol açtı̆̆ 1 ve bunun da ağrının kronikleşmesine sebep olduğu bildirilmektedir (10, 13, 16, 17). Patofizyolojik açıdan bakıldığında servikal kas iskelet sistemi bozuklukları ile en ilişskili primer baş ağrısının GTBA olduğu düşünülmektedir. $\mathrm{Bu}$ nedenle, GTBA'da servikal kas iskelet bozukluklarını araştıran ve bunlara yönelik tedavileri içeren çalışma sayısının daha fazla olduğu görülmektedir $(13,18) . \quad \mathrm{Bu}$ araştırmalarda GTBA'lı bireylerde ileri baş postürü, servikal mobilite, servikal kas fonksiyonları, tetik noktalar, kas hassasiyeti ve basınç ağrı eşiği gibi birçok servikal bölge kas iskelet sistemi değerlendirmesinin yapıldı̆̆ 1 dikkat çekmektedir.

GTBA ve ileri baş postürü: İleri baş postürü, başın gövdeye göre öne doğru yer değiştirmesi olarak tanımlanmaktadır. Baş ağrılı bireylerde sıç̧a görülen ileri baş postürünün değerlendirilmesi, kullanılması gereken servikal bölge değerlendirmelerinden biri olarak önerilmektedir. İleri baş postürünün değerlendirmesinde en yaygın kullanılan yöntemin kraniovertebral açı ölçümü olduğu görülmektedir. Kraniovertebral açının azalması daha şiddetli ileri baş postürünü göstermektedir. İleri baş postürü genellikle C7'den geçen yatay çizgi ile kulağın tragusundan C7'ye uzanan bir çizgi arasındaki açı hesaplanarak ölçülmektedir. Epizodik ve kronik GTBA'lı hastaların sağl1klılara göre ileri baş postürüne sahip olduğu birçok çalışmada gösterilmiştir (13, 19, 20). Son y1llarda bu konuyla ilgili yapılan bir meta-analizde, GTBA hastalarında ileri baş postürünü gösteren çalışmaların bulunduğu; fakat çalışmaların kanıt düzeyinin düşük olduğu, bu nedenle GTBA ile ileri baş postürü arasındaki 
ilişkinin anlaşılması için daha fazla çalışma yapılması gerektiği belirtilmektedir (13).

GTBA ve azalmış servikal mobilite: GTBA hastalarında servikal mobilite incelemesinde eklem hareket açıklığı değerlendirmesinin sıklıkla kullanıldı̆̆ görülmektedir. Birçok çalışmada kronik ve epizodik GTBA'lı hastaların, sağlıklı bireylerle karşılaştırıldığında servikal fleksiyon, lateral fleksiyon, sağ ve sol rotasyon eklem hareket açıklığının azalmış olduğu bildirilmektedir $(13,19,20)$.

GTBA ve yetersiz servikal bölge kas fonksiyonları: GTBA'l1 hastalarda servikal kas kuvvetindeki yetersizliklerin bu bölgedeki yapıların daha fazla strese maruz kalmasına neden olacağı ve bunun da baş ağrısını tetikleyebileceği hipotezi ile yapılan çalışma sayısının her geçen gün arttığ 1 görülmektedir. Liang ve arkadaşları yaptıkları meta-analizde, sağlıklı kontrollerle karşıllaştırıldığında GTBA'lı bireylerin boyun fleksör ve ekstansör kaslarının kuvvetinde önemli bir azalma olmadığını ifade etmektedir (13).

Diğer taraftan başka bir sistematik derlemede Abboud ve arkadaşları kronik GTBA hastalarında hem fleksör hem de ekstansör boyun kaslarının kuvvetinde azalma olduğuna işaret etmiştir. Ek olarak rehabilitatif ultrason çalışmaları da bu sonucu destekler şekilde kronik GTBA'l1 hastalarda sağlıklı kontrollere kıyasla servikal ekstansör kas kesit alanının daha küçük olduğunu belirtmektedir (19).

GTBA'lı hastalarda yüzeyel servikal kasların kuvvetinin yanı sıra derin servikal fleksör kasların kuvvetinin ve enduransının değerlendirildiği çalışmalar da bulunmaktadır. GTBA'lı hastalarda sağlıklı kontrollere göre derin servikal fleksör kasların aktivasyonunun ve enduransının azaldığını bildiren çalışma sayısı her geçen gün artmaktadır (19, 20, 21). Görüldüğü gibi bu sonuçlar GTBA ile yüzeyel ve derin servikal kasların kuvveti ve enduransı arasında bir ilişki olabileceğini göstermektedir.

GTBA ve tetik noktalar, kas hassasiyeti ve basınç ăgrı eşiği: Tetik noktalar gergin bir iskelet kası bandı içindeki aşırı hassas noktalar olarak tanımlanmaktadır (19). GTBA'lı hastalarda tetik noktaların sik bulunduğu ve genellikle servikal kas iskelet sistemi bozukluğunun kanıtı olarak kabul edildiği veya santral sensitizasyondan kaynaklanabileceği bildirilmektedir (13). Çalışmalar, sağlıklı kişilere göre GTBA'lı hastalarda trapez, temporal, sternokleidomastoid ve suboksipital kaslarda daha fazla sayida aktif veya latent tetik nokta olduğunu bildirmektedir (19). Ayrıca GTBA'nın ayırıcı tanısında palpasyonla kas hassasiyeti kriteri bulunmaktadir (1). Kas hassasiyetinin değerlendirildiği çalışmalarda sağlıklı kontrollere göre kronik GTBA'l1 hastaların daha yüksek hassasiyet skorları gösterdiği belirtilmektedir $(17,19)$.

Basınç ağrı eşiğinin değerlendirildiği çalışmaların çoğunda da, kronik ve epizodik GTBA hastalarında sağlıklı kontrollere göre trapez, frontal ve temporal kaslarda basınç ağrı eşiğinin daha düşük olduğu bildirilmektedir (19).

\section{Migren}

GTBA'dan sonra en sık görülen primer baş ağrısı migrendir. Populasyonda görülme sıklığı GTBA'dan sonra gelmesine rağmen ağrı şiddetinin ve eşlik eden diğer semptomların daha fazla olmasından dolayı hekime başvuruda birinci sıradadır. Migren 
patogenezinin temelinde, başın ağr1 duyusunu algılayan trigeminal siniri, üst servikal sinirleri ve bunlar tarafindan inerve olan meninksleri ve kan damarlarını kapsayan trigeminoservikovasküler sistem aktivasyonunun yattı̆̆ düşünülmektedir (21). Migren patofizyolojisinde trigeminal nukleus konverjansının etkili olduğu, trigeminal nukleustaki hassasiyetin superior salivatör nukleus arasındaki bağlantıyla dural vazodilatasyona ve nörojenik inflamasyona da katkıda bulunduğu belirtilmektedir (13). Patofizyolojik açıdan bakıldığında migrenin servikal kas iskelet sistemi bozuklukları ile GTBA'dan daha uzak bir ilişki gösterdiği düşünülmektedir. Fakat bu düşüncenin değişmeye başladığı ve son yıllarda migren hastalarında da servikal kas iskelet sistemi ile ilgili değerlendirme ve tedavilerin çalışmalarda öne çıktığ 1 görülmektedir (13, 21-24).

Migren ve ileri baş postürü: Migren hastalarında ileri baş postürü değerlendirmesinin birçok çalışmada kullanıldığı fakat sonuçların çelişkili olduğu görülmektedir. Yapılan çalışmaların bir kısmında migren hastalarının sağlıklı bireylerle karşılaştırıldıklarında daha şiddetli ileri baş postürüne sahip oldukları belirtilirken (11, 25-28); bazı çalışmalarda migren hastaları ve sağlıklı kontroller arasında ileri baş postürü açısından bir farklılık olmadı̆̆ 1 bildirilmiştir $(13,29)$. Yakın zamanda yapılan bir meta analizde, migrenli bireylerde ileri baş postürü görülmesi ile ilgili kanıtların orta düzeyde olduğu belirtilmektedir (13).

Migren ve azalmış servikal mobilite: Migrenli hastalarda servikal eklem hareket açıklığının değerlendirildiği çalışmalarda, sağlıklı bireylerle karşılaştırıldığında servikal eklem hareket açıklığının azaldığı belirtilmektedir (11, 26, 29). Baz1 çalışmalar, sadece servikal ekstansiyon ve toplam fleksiyon ekstansiyon eklem hareket açıklığında azalma bildirirken, bazı çalışmaların sadece sağ ve sol rotasyon eklem hareket açıklıklarında azalma bildirdiği görülmektedir (26, 29). Diğer taraftan yapılan çalışmaların kanıt düzeyinin incelendiği bir meta-analizde, migrende servikal eklem hareket açıklığının azaldığını gösteren sonuçların kanıt düzeyinin çok düşük olduğu belirtilmektedir (13).

Servikal eklem hareket açıklığ değerlendirmesinin yanı sira migrenli hastalarda üst servikal bölge eklem hareketliliğini değerlendirmek için fleksiyon rotasyon testinin de kullanıldığ görülmektedir. Migrenli hastalarda boyun ağrısı varlığında üst servikal omurga hareketliliğinde daha fazla kısıtlılık olduğu belirtilmektedir $(11,27) . \mathrm{Bu}$ sonucu destekleyen başka bir çalışmada da epizodik veya kronik migren hastalarının sağlıklı kontrollere göre üst servikal omurga eklem mobilitesinin önemli derecede azaldığ 1 gösterilmiştir (28). Üst servikal omurganın manuel değerlendirmeleri de bu sonucu desteklemekte ve epizodik veya kronik migren hastalarında özellikle C1-2 servikal eklemde hipomobilite olduğu bildirilmektedir $(11,27,28)$.

Migren ve yetersiz servikal bölge kas fonksiyonu: Migrenli hastalarda servikal kas fonksiyonunun incelendiği çalışmalarda yüzeyel servikal kas kuvvet ve enduransı ile derin servikal fleksörlerin koaktivasyonunun değerlendirildiği görülmektedir. Yüzeyel kasların kuvvetinin değerlendirmesinde, migren hastalarında servikal ekstansör ve fleksör kasların 
kuvvetinin daha düşük olduğu ve daha yüksek bir ekstansör / fleksör kas gücü oran1 gösterdiği bildirilmektedir (11, 30). Başka bir çalışmada da kronik migren hastalarının sağlıklı kontrollere ve epizodik migrenli hastalara göre daha düşük servikal ekstansör kas kuvveti gösterdikleri ve servikal fleksiyon ve sol lateral fleksiyon sırasında tepe kuvveti oluşturmak için önemli ölçüde daha fazla zaman harcadıkları belirtilmektedir (31). Migrenli hastalarda kas endurans1 değerlendirmesinde de sağlıklı kontrollere ve SBA hastalarına göre, servikal fleksör ve ekstansör kaslarının daha düşük dayanıklılık gösterdikleri bildirilmiştir (11).

Migrenli hastalarda yüzeyel servikal kasların yanı sıra derin fleksör kasların da değerlendirildiği görülmektedir. Derin fleksör kasların aktivasyonunda migrenli hastaların sağlıklı kontrollerle karşılaştırıldığında kranioservikal fleksiyon testinde daha kötü performans gösterdikleri ve testin son aşamasında daha yüksek bir elektromiyografik ekstansör / fleksör kas aktivitesi oranına sahip oldukları belirtilmektedir $(27,28,30)$. Migren hastalarında kas fonksiyonu yetersizliklerini bildiren çalışmaların yanı sıra, servikal yüzeyel kas kuvveti ve kranioservikal fleksiyon testi performans1 açısından önemli bir farklılık olmadığını bildiren çalışmaların da bulunduğu, fakat bu çalışma sayılarının az olduğu görülmektedir $(13,39)$.

Migren ve yetersiz servikal esneklik: Migrenli hastalarda servikal bölge kas esnekliğinin çok az sayıda çalışmada değerlendirildiği görülmektedir. Bir çalışmada, migren hastalarında sağliklı kontrollerle karşılaştırıldığında trapez, sol sternokleidomastoid ve sağ oksipital kaslarda esnekliğin azaldığı ve germe esnasında daha fazla ağrı olduğu bildirilmektedir (29).

Migren ve tetik noktalar, basınç ăgrı eşiği: Migrenli hastaların sağlıklı kontrollere göre daha fazla sayida aktif tetik noktaya sahip olduğu ve en çok etkilenen kasların suboksipital, üst trapez, sternokleidomastoid ve temporal kaslar olduğu bildirilmektedir (11, 13, 25-29).

Ayrıca migrenli hastalarda kontrollere göre üst trapez, sternokleidomastoid, suboksipital, ön skalen, levator skapula ve mastoid kaslarının basınç ağrı eşiklerinin önemli ölçüde daha düşük olduğu ve bunun da duyarlı bir sinir sistemini gösterdiği belirtilmektedir (11-13).

\section{Servikojenik Baş Ağrısı}

Servikojenik baş ağrısı, sınıflamada sekonder baş ağrıları arasında yer alan, servikal kas iskelet sistemi bozukluğu kaynaklı baş ağrısı tanımıyla, servikal omurga ile en ilişkili baş ağrısı alt grubudur (1). Yapılan çalışmalarda genel toplumda SBA prevalansının \%0,4-2,5 ve kronik baş ağrısı olanlarda ise \%15-20 arasında olduğu belirtilmektedir (32). SBA patofizyolojisi tam olarak bilinmemesine rağmen, ağriya neden olan yapılar; suboksipital kaslar, C12 sinir kökü, C 2-3 intervertebral disk, üst servikal ligament ve sinoviyal eklemler olarak bildirilmektedir (33).

Servikal omurga ile en ilişkili baş ağrısı tipi olmasına rağmen, literatürde SBA hastalarında servikal kas iskelet sistemi bozukluklarını inceleyen çalışmaların daha az sayıda olduğu ve güncel verilerin yetersiz olduğu görülmektedir.

SBA ve ileri baş postürü: SBA'lı hastalarda ileri baş postürü değerlendirme sonuçlarının 
çelişkili olduğu, SBA'lı hastaların sağlıklı kontrollerle karşılaştırıldığında, bu hastalarda ileri baş postürü varlığını bildiren çalışmaların yanı sıra anlamlı farklılık göstermediğini belirten çalışmaların da olduğu görülmektedir (3436).

SBA ve azalmış servikal mobilite: Servikal eklem hareket açıklığı değerlendirilmesine yönelik çalışmalarda, SBA'lı hastaların sağlıklı kontrollere göre servikal mobilitelerinin yetersiz olduğu birçok çalışmada bildirilmektedir (36-39, 41). Fakat eklem hareket açıklığ k kısıtlılık yönünün çalışmalarda farklılık gösterdiği; bazı çalışmalarda fleksiyon ekstansiyon yönlerinde (36), bazı çalışmalarda sadece ekstansiyon yönünde $(38,39)$, bazı çalışmalarda ise sağ ve sol rotasyon yönlerinde (36) kisitlilık olduğu bildirilmektedir.

SBA'lı hastalarda ayrıca üst servikal omurga mobilitesinin değerlendirilmesine yönelik fleksiyon rotasyon testinin de yaygın kullanıldığı görülmektedir. SBA hastalarında sağlıklı kontrollere göre fleksiyon rotasyon testi sonuçlarının bu hastalarda azalmış üst servikal omurga mobilitesine işaret ettiği bildirilmektedir $(38,40)$.

Eklem mobilitesini değerlendirmek için yaygın kullanılan bir diğer yöntem olan manuel değerlendirmede de SBA hastalarında özellikle üst servikal omurga hareketliliğinin sağlıklı bireylere göre azalmış olduğu ve mobilizasyonun ağrılı olduğu bildirilmektedir $(34,36,39,42)$.

SBA ve yetersiz servikal bölge kas fonksiyonu: SBA'lı hastalarda yüzeyel fleksör ve ekstansör kas kuvvetinin değerlendirildiği çalışmalarda, sağlıklı kontrollere göre hem fleksör hem de ekstansör kas kuvvetlerinde azalma olduğu belirtilmektedir $\quad(34, \quad 36, \quad 42) . \quad \mathrm{Bu}$ çalışmalarda kas enduransının ise sadece fleksör kaslarda azaldığı bildirilmiştir (34, $36,42)$.

SBA'lı hastaların kranioservikal fleksiyon testinde de sağlıklı kontrollere göre daha kötü performans gösterdiği bildirilmektedir (42). $\mathrm{Bu}$ hastalarda derin servikal fleksörlerin kuvvet ve enduransinın az olmasının yanı sira, bu hastaların test esnasinda farklı bir motor strateji sergilediği, daha fazla sternokleidomastoid kas1 aktivitesi gösterdiği belirtilmektedir (42). Bu sonuçlar SBA'lı hastalarda hem yüzeyel hem derin servikal kasların özellikle de derin servikal fleksör kasların zayıf olduğunu göstermektedir.

Son yıllarda yaygınlaşan rehabilitatif ultrason çalışmaları servikal bölge kas fonksiyonlarının incelenmesine yeni bir boyut getirmiştir. Bu çalışmalarda servikal bölge kaslarının kesit alanları incelenmekte, böylece kaslarda meydana gelen yapisal değişiklikler klinik değerlendirmelerle birlikte yorumlanabilmektedir. Bir çalışmada SBA'lı hastalarda, semispinalis kapitis kası için semptomatik tarafta, semptomatik olmayan tarafa kiyasla azalmış enine kesit alanı gösterilirken, başka bir çalışmada longus kolli kasının kesit alanında bir fark gözlenmediği belirtilmektedir (37, 43). Bir başka çalışmada ise, SBA'lı yaşlı kadınlarda rektus kapitis posterior majör ve multifidus kaslarının enine kesit alanlarının önemli ölçüde daha az olduğu, ayrıca rektus kapitis posterior majör ve minör ve splenius kapitis kaslarında daha fazla yağ infiltrasyonu görüldüğü bildirilmektedir (44). 


\section{SONUÇ VE ÖNERİLER}

Sonuç olarak; GTBA, migren ve SBA'nın servikal kas iskelet sistemi bozuklukları ile ilişkili olduğu, farklı patofizyolojik mekanizmalara sahip olmalarına rağmen bu üç baş ağrısı tipinde de birçok servikal kas iskelet sistemi bozukluğunun bulunduğu bildirilmektedir.

GTBA ve servikal kas iskelet sistemi bozuklukları ile ilişkili çalışma sonuçlarının migrenden daha net olduğu görülmektedir. Birçok çalışmada GTBA'lı hastalarda ileri baş postürü, azalmış servikal mobilite, yetersiz servikal kas fonksiyonu, artmış tetik nokta sayısı, kas hassasiyeti ve düşük basınç ağrı eşiği gibi servikal kas iskelet sistemi bozukluklarının bildirildiği görülmektedir. Bunun yanı sıra GTBA'l1 hastalarda özellikle yüzeyel servikal kas kuvvetinin yetersizliği ile ilgili çalışma sonuçlarının çelişkili olduğu görülmektedir.

Migren hastalarında da GTBA hastaları ile benzer servikal kas iskelet sistemi değerlendirmelerinin yapıldı ğ 1 görülmektedir. Migrenin ileri baş postürü, azalmış servikal mobilite, yetersiz servikal kas fonksiyonu ve servikal esneklik, artmış tetik nokta sayısı ve düşük basınç ağrı eşiği gibi servikal kas iskelet sistemi bozuklukları ile ilişkili olduğu birçok çalışmada bildirilmektedir. Fakat az sayıda çalışmada migrenli hastalarda ileri baş postürü ve azalmış yüzeyel servikal kas kuvveti görülmediği, sağlıklı bireylerle benzer oldukları belirtilmektedir.

SBA'lı hastalarda azalmış servikal mobilite ve yetersiz servikal kas fonksiyonu bulunduğu birçok çalışmada belirtilmektedir. Fakat bu hastalarda da migren hastalarında olduğu gibi ileri baş postürü sonuçlarının çelişkili olduğu; bazı çalışmalarda SBA'lı hastaların ileri baş postürüne sahip olduğu, bazılarında sağlıklı bireylerden farklı olmadikları bildirilmektedir. Ayrica SBA'lı hastalarda görülen servikal kas iskelet sistemi bozuklukları ile ilgili güncel çalışmaların yetersiz olduğu dikkat çekmektedir.

"Servikal kas iskelet sistemi bozuklukları baş ağrısına bir neden olabilir mi?” veya tam tersi "Baş ağrısı servikal kas iskelet sistemi bozukluklarına neden olur mu?" soruları uzun süre araştırılacak gibi görünmektedir. Bunun yanı sıra, baş ve servikal bölgenin anatomik, fizyolojik ve fonksiyonel bağlantıları sebebiyle, servikal bölgenin baş ağrısına veya baş ağrısının servikal bölgeye etkisinin göz ard1 edilemeyeceği açıktır. İncelediğimiz üç baş ağrısı tipi için servikal kas iskelet sistemi bozukluklarını bildiren çalışma sayısının her geçen gün arttığ 1 görülmüştür. Bu üç baş ağrısı tipi için de özellikle ileri baş postürü ve azalmış yüzeyel servikal kas kuvveti ile aralarındaki ilişkinin daha net anlaşılabilmesi için kalite düzeyi yüksek ve daha fazla sayıda çalışmaya ihtiyaç olduğunu düşünmekteyiz. Bu alanda çalışan klinisyenlere ve araştırmacılara önerimiz baş ağrılı hastalarda baş ve boynu bir bütün olarak ele almaları ve kapsamlı bir servikal kas iskelet sistemi değerlendirmesi yapmalarıdır.

Sınırlılıklar: $\mathrm{Bu}$ derlemenin en önemli limitasyonu, kullanılan çalışmaların kanıt düzeyinin göz önünde bulundurulmamasidir. Gelecek derlemelerde kanıt düzeyi yüksek çalışmaların kullanılmasına dikkat edilmelidir. Ayrica bu derlemede sadece GTBA, migren ve SBA hastalarındaki incelenmiştir. Gelecek çalışmalarda diğer baş ağrısı tipleri ile servikal kas iskelet 
sistemi bozuklukları arasındaki ilişkiler de incelenmelidir.

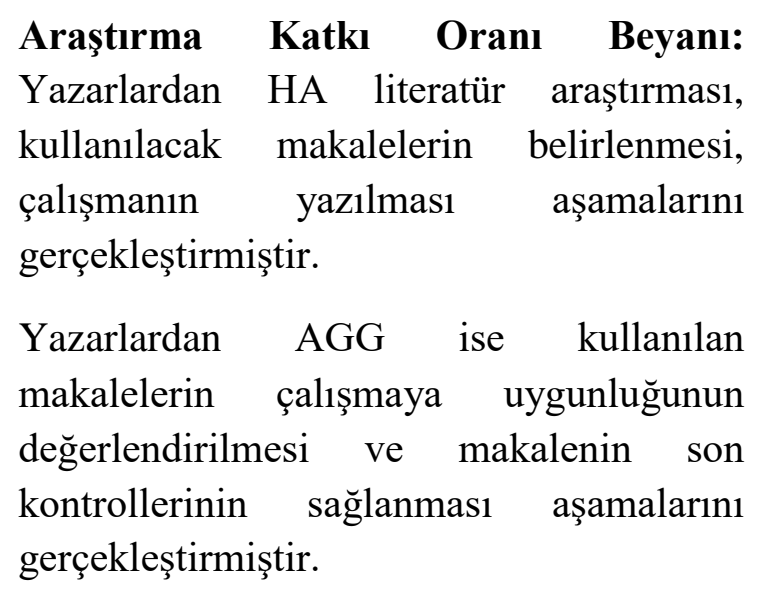

Maddi Destek/Teşekkür: Çalışma esnasında herhangi bir kişiden veya kuruluştan maddi destek alınmamıştır.

Çıkar Çatışması: Yazarlar çıkar çatışması olmadığını beyan ederler.

\section{KAYNAKLAR}

1. Headache Classification Committee of the International Headache Society (IHS). The International Classification of Headache Disorders, $3^{\text {rd }}$ edition International Headache Society 2018. Cephalalgia. 2018; 38(1): 1211.

2. Machado-Oliveira L, Da Silva Gauto YO, De Santana Neto FJ, Da Silva MG, GermanoSoares AH, Diniz PRB. Effects of Different Exercise Intensities on Headache A Systematic Review. Am J Phys Med Rehabil. 2020; 99: 390-396.

3. Fernández-de-las-Peñas C, Florencio LL, PlazaManzano G, Arias-Buría JL. Clinical Reasoning Behind Non-Pharmacological Interventions for the Management of Headaches: Narrative Literature Review. Int J Environ Res Public Health. 2020; 17(4126): 1-17.

4. Rubio-Ochoa J, Benítez-Martínez J, Lluch E, Santacruz-Zaragoz S, Gomez-Contreras $\mathrm{P}$, Cook CE. Physical examination tests for screening and diagnosis of cervicogenic headache: A systematic review. Man Ther. 2016; 21: 35-40.

5. Mitsikostas DD, Ashina M, Craven A, Diener HC, Goadsby PJ, Ferrari MD. et al. European headache federation consensus on technical investigation for primary headache disorders. $\mathbf{J}$ Headache Pain. 2016; 17(5): 1-8.

6. Vos T, Flaxman AD, Naghavi M, Lozano R, Michaud C, Ezzati M. et al. Years lived with disability (YLDs) for 1160 sequelae of 289 diseases and injuries 1990-2010: a systematic analysis for the global burden of disease study 2010. Lancet. 2012; 15,380(9859): 2163-2196.

7. Howard PD, Behrns W, DiMartino M, DiMambro A, McIntyre K, Shurer C. Manual examination in the diagnosis of cervicogenic headache: a systematic literature review. J Man Manip Ther. 2015; 23(4): 210-218.

8. Luedtke K, Boissonnault W, Caspersen N, Castien R, Chaibi A, Falla D. et al. International consensus on the most useful physical examination tests used by physiotherapists for patients with headache: A Delphi study. Man Ther. 2016; 23: 17-24.

9. Jull G, Hall T. Cervical musculoskeletal dysfunction in headache: How should it be defined? Musculoskelet Sci Pract. 2018; 38: 148-150.

10. Castien R, De Hertogh W. A Neuroscience Perspective of Physical Treatment of Headache and Neck Pain. Front Neurol. 2019; 10: 276.

11. Carvalhoa GF, Schwarzc A, Szikszaya TM, Adamczyka WM, Bevilaqua-Grossic D, Luedtke K. Physical therapy and migraine: musculoskeletal and balance dysfunctions and their relevance for clinical practice.Braz J Phys Ther.2020; 24(4): 306-317.

12. Florencio LL, Giantomassi MCM, Carvalho GF, Goncalves MC, Dach F, Fernandez-de-lasPenas C. et al. Generalized Pressure Pain Hypersensitivity in the Cervical Muscles in Women with Migraine. Pain Med. 2015; 16: 1629-1634.

13. Liang Z, Galea O, Thomas L, Jull G, Treleaven J. Cervical musculoskeletal impairments in migraine and tension type headache: A systematic review and meta-analysis. Musculoskelet Sci Pract. 2019; 42: 67-83.

14. Bogduk N. The neck and headaches. Neurol Clin. 2014; 32: 471-487.

15. Bartsch T. Migraine and the neck: new insights from basic data. Curr Sci. 2005; 9: 191-196.

16. Ferna'ndez-de-las-Penas C, Ferna'ndezMayoralas DM, Ortega-Santiago R, AmbiteQuesada S, Palacios-Cena D, Pareja JA. Referred pain from myofascial trigger points in head and neck-shoulder muscles reproduces 
head pain features in children with chronic tension type headache. J Headache Pain. 2011; 12: $35-43$.

17. Lidegaard M, Andersen LL. Association Between Trapezius Muscle Tenderness and Tension-Type Headache in Female Office Workers: A Cross-sectional Study. J Manipulative Physiol Ther. 2018; 41: 483-487.

18. Ferna'ndez-de-las-Penas C, Cuadrado ML. Physical therapy for headaches. Cephalalgia. 2016; 36(12): 1134-1142.

19. Abboud J, Marchand AA, Sorra K, Descarreaux M. Musculoskeletal physical outcome measures in individuals with tension-type headache: A scoping review. Cephalalgia. 2013; 33(16): 1319-1336.

20. Ferna'ndez-de-Las-Penas C, Cuadrado ML, Pareja JA. Myofascial trigger points, neck mobility, and forward head posture in episodic tension-type headache. Headache. 2007; 47: 662-672.

21. Edvinsson JCA, Viganò A, Alekseeva A, Alieva E, Arruda R, De Luca C. et al. The 5th cranial nerve in headaches.J Headache Pain.2020;21:65

22. Rohmann JL, Rist PM, Buring JE, Kurth T. Migraine, headache, and mortality in women: a cohort study. J Headache Pain. 2020; 21: 27.

23. Lemmens J, De Pauw J, Van Soom T, Michiels S, Versijpt J, Van Breda E. et al. The effect of aerobic exercise on the number of migraine days, duration and pain intensity in migraine: a systematic literature review and meta-analysis. J Headache Pain. 2019; 20: 16.

24. Côté P, Yu H, Shearer HM, Randhawa K, Wong JJ, Mior S, et al. Non-pharmacological management of persistent headaches associated with neck pain: a clinical practice guideline from the Ontario protocol for traffic Injury management (OPTIMa) collaboration. Eur J Pain. 2019; 23: 1051-1070.

25. Ferracini GN, Chaves TC, Dach F, BevilaquaGrossi D, Ferna'ndez-de-las-Penas C, Speciali JG. Relationship Between Active Trigger Points and Head/Neck Posture in Patients with Migraine. Am J Phys Med Rehabil. 2016; 95(11): 831-839.

26. Fernández-de-las-Peñas $\mathrm{C}$, Cuadrado $\mathrm{ML}$, Pareja JA. Myofascial trigger points, neck mobility and forward head posture in unilateral migraine. Cephalalgia. 2006; 26: 1061-1070.

27. Bragatto MM, Bevilaqua-Grossi D, Benatto MT, Lodovichi SS, Pinheiro CF, Carvalho GF. et al. Is the presence of neck pain associated with more severe clinical presentation in patients with migraine? A cross-sectional study. Cephalalgia. 2019; 39(12): 1500-1508.

28. Luedtke K, Starke W, May A. Musculoskeletal dysfunction in migraine patients. Cephalalgia. 2018; 38(5): 865-875.

29. Horwitz S, Stewart A. An Exploratory Study to Determine the Relationship between Cervical Dysfunction and Perimenstrual Migraines. Physiother Can. 2015; 67(1): 30-38.

30. Benatto MT, Florencio LL, Bragatto MM, Lodovichi SS, Dach F, Bevilaqua-Grossi D. Extensor/flexor ratio of neck muscle strength and electromyographic activity of individuals with migraine: a cross-sectional study. Eur Spine J. 2019; 28: 2311-2318.

31. Florencio LL, Oliveira AS, Carvalho GF, Tolentino GA, Dach F, Bigal ME, et al. Cervical Muscle Strength and Muscle Coactivation During Isometric Contractions in Patients With Migraine: A Cross-Sectional Study. Headache. 2015; 55: 1312-1322.

32. Abaspour O, Akbari M, Rezasoltani A, Ahmadi A. Relationship between thickness of deep neck muscles synergy and painful side in patients with cervicogenic headache. Cranio. 2019; 1-7

33. Antonaci F, Inan LE. Headache and neck. Cephalalgia. 2020; 1-5.

34. Zito G, Jull G, Story I. Clinical tests of musculoskeletal dysfunction in the diagnosis of cervicogenic headache. Man Ther. 2006; 11: 118-129.

35. Farmer PK, Snodgrass SJ, Buxton AJ, Rivett DA. An investigation of cervical spinal posture in cervicogenic headache. Phys Ther. 2015; 95 : 212-222.

36. Dumas J-P, Arsenault AB, Boudreau G, Magnoux E, Lepage Y, Bellavance A. et al. Physical impairments in cervicogenic headache: traumatic vs. nontraumatic onset. Cephalalgia. 2001; 21: 884-893.

37. Jull G, Amiri M, Bullock-Saxton J, Darnell R, Lander C. Cervical musculoskeletal impairment in frequent intermittent headache, part 1 : subjects with single headaches. Cephalalgia. 2007; 27: 793-802.

38. Snodgrass SJ, Cleland JA, Haskins R, Rivett DA. The clinical utility of cervical range of motion in diagnosis, prognosis, and evaluating the effects of manipulation: a systematic review. Physiotherapy. 2014; 100: 290-304. 
39. Uthaikhup S, Sterling M, Jull G. Cervical musculoskeletal impairment is common in elders with headache. Man Ther. 2009; 14: 636641.

40. Hall T, Robinson K. The flexion-rotation test and active cervical mobility-a comparative measurement study in cervicogenic headache. Man Ther. 2004; 9: 197-202.

41. Mingels S, Granitzer M. Habitual Cervical Posture in Women With Episodic Cervicogenic Headache Versus Asymptomatic Controls. J Manipulative Physiol Ther. 2020; 43: 171-178.

42. Makofsky HW, Douris P, Goldstein LB, Discepolo A, Grion K, Kushnir G. et al. The Effect of the PostureJac on Deep Cervical
Flexor Endurance: Implications in the Management of Cervicogenic Headache and Mechanical Neck Pain. Cranio. 2012; 30(1) :187-193.

43. Abaspour O, Javanshir K, Amiri M, Karimlou M. Relationship between cross sectional area of Longus Colli muscle and pain laterality in patients with cervicogenic headache. J Back Musculoskelet Rehabil. 2015; 28(2): 393-399.

44. Uthaikhup S, Assapun J, Kothan S, Watcharasaksilp K, Elliott JM. Structural changes of the cervical muscles in elder women with cervicogenic headache. Musculoskelet Sci Pract. 2017; 29: 1-6. 